\title{
Rock Mass Rating spatial estimation by geostatistical analysis
}

\author{
F. Ferrari*, T. Apuani, G.P. Giani \\ Università degli Studi di Milano, Dipartimento di Scienze della Terra “Ardito Desio"via Mangiagalli 34, 20133 Milano, Italy
}

\section{A R T I C L E I N F O}

\section{Article history:}

Received 13 December 2012

Received in revised form

18 December 2013

Accepted 29 April 2014

\section{Keywords:}

Geomechanical survey

Geostatistics

Rock Mass Rating

San Giacomo Valley

\begin{abstract}
A B S T R A C T
This work aims to estimate the Rock Mass Rating of $200 \mathrm{~km}^{2}$ area of the Italian Central Alps, along San Giacomo Valley (province of Sondrio). The regional geological setting is related to the Pennidic Nappe arrangement, which is characterized by the emplacement of sub-horizontal gneissic bodies, separated by meta-sedimentary cover units. The resulting RMR map can be a useful tool to forecast the quality of outcropping rock masses as well as to derive their geomechanical behaviour. Almost 100 geomechanical field surveys have been carried out in the research area, in order to characterize the outcropping rock masses; afterwards rock mass quality indexes have been evaluated in each surveyed site. In order to estimate the Rock Mass Rating values in un-sampled locations, different geostatistical techniques (kriging and simulations) have been applied, using both bi-dimensional and almost three-dimensional approaches. The validation process shows that kriging tends to produce smoothened distributions, while conditional simulations allow respecting local extreme values. Although geostatistical analysis reveals that geomechanical properties show spatial correlations, it is to remind that rock mass quality is strongly related to its geological and structural history.
\end{abstract}

(c) 2014 Elsevier Ltd. All rights reserved.

\section{Introduction}

The knowledge of rock mass quality indexes in an extended area is an important prerequisite in design of civil engineering and mining activities; the Rock Mass Rating [1] (RMR) is a widely used index to evaluate geomechanical features and stability conditions in areas of interes for the planning and construction of large-scale engineering works, or affected by rock slope stability problems. The RMR classification has found wide applications in various types of engineering projects (such as tunnels, foundations and mines), as well as in geological risk management. The accuracy degree in predicting, evaluating and interpreting the quality of rock masses, for instance a tunnel alignment, is a key for the successful execution of the project. Actually, the RMR is one of the rock mass classification systems which, as well as the Qsystem [2], can be used as a guideline for the selection of the appropriate excavation technique, the kind of rock reinforcements and permanent support in tunnels, for the prevision of stand-up time, and for deriving the deformability parameters of the rock mass. At the same time, the RMR can also be used to evaluate the landslide susceptibility of rock slopes, allowing one to identify the more critical portions of rock masses that could be prone to failure. For instance, rockfall analysis needs an accurate study of the cliff and the localization of the source areas of blocks. In addition, the

\footnotetext{
* Corresponding author. Tel.: + 39 0250115501; fax: + 390250115494.

E-mail address: federica.ferrari@unimi.it (F. Ferrari).
}

rock mass quality affects the choice of the conceptual model used in numerical modelling and analysis: a highly fractured rock mass, with respect to the geological and engineering problem, can be modelled as an equivalent continuum media, while a massive rock mass, with few discontinuities, must be approached with a discrete model.

In preliminary studies, it is a common practice to execute direct geomechanical surveys in few representative areas, where the logistic difficulties can be bypassed, reducing time and costs. In both applications (civil works and slope stability), the common measurement techniques of rock mass properties provide pointwise values, referred to a specific sampling location. Therefore the reproduction of the spatial variability of geomechanical quality in the whole area can be a very useful tool, especially during the prefeasibility and feasibility planning phases, particularly to individuate critical points.

This paper focuses on the estimation of the RMR values in the shallow rock masses of San Giacomo Valley (Italian Central Alps), far from the measurement locations. This valley is characterized by high sub-vertical rock cliffs, incumbent on infrastructures and villages; in this valley, slope instability problems are quite frequent. The last one, involving a rock volume of $20,000 \mathrm{~m}^{3}$, occurred in September 2012, and obstructed the main road, isolating the villages of the upper San Giacomo Valley for few days. It follows that the safeguard of the territory, the protection of elements at risk, together with the necessity of touristic and commercial development, rend necessary the implementation of the transportation network, with roads hewn out of the rock face, 
halfway up the hill, as well as in underground. The availability of a continuous map of RMR values can therefore be used in land use planning, prevention, mitigation and management of risks, but also in the prevision of the behaviour of rock masses.

The number and distribution of outcrops often constrains the quantitative description of rock mass properties, therefore indirect techniques, such as geostatistical methods, have been suggested to estimate rock mass characteristics in the whole area [3-5], so that the study of variations of rock mass features, in relation with the distance between survey points, can reveal spatial correlation structures. The theory of regionalized variables [6], afterwards shortened by the mining engineering community to the term "geostatistics", is able to incorporate these structures, which mean spatial dependence of regionalized variable at different locations in space.

Several authors have applied the geostatistical approach to analyze rock mass fracture-distribution [7-15] or rock mass specific properties [16-23]. The RMR index has been estimated using geostatistical analysis since 2004 [24-31], especially for tunnel projects; the kriging method has usually been applied to borehole data, sometimes integrated by geophysical surveys, with a secondary and only qualitative role. RMR values have always been considered as a single regionalized variable, and not as the sum of more variables.

Another very popular index of rock mass quality is the Q-system, which was developed for depth rock mass classification and tunnel applications. The Q-index has been successfully estimated, as a single variable, by geostatistical techniques, studying also its effects on the Tunnel Boring Machine related parameters [29].

In the San Giacomo Valley, considering the main demand in land use planning and the lack of data regarding depth rock masses, only the RMR has been considered; in this paper only field superficial measurements have been used as input to estimate the RMR values. The main innovation consists of RMR estimation in a wider area than those of the previously cited works; in fact, this research has been carried out at regional scale. The results obtained by applying two different approaches (2D and almost 3D one) and techniques (kriging and simulations) have been validated, compared and discussed.

\section{Geological setting}

The study area is located in the Italian Central Alps (Fig. 1a); it is aligned along the San Giacomo Valley (province of Sondrio), which is situated between Lake Como and the Splügen Pass, which connects Italy to Switzerland. San Giacomo Valley has an extent of about $200 \mathrm{~km}^{2}$ and its morphology results from its structural and glacial evolution.

The Central Northern Alps are a fold and thrust system, belonging to the Alpine nappe pile, which was created in a subduction zone environment during the closure of Piemontais and Valaisan oceans. The major thrust sheets developed during the Alpine compressional phase and imbricated from South to North, forming, in the region of interest, the Pennidic Nappe arrangement. The Penninic units were emplaced by thrusting, towards NW, in the early Tertiary [32]. In particular, the research area pertains to the upper Penninic units which have been considered to be an orogenic wedge, consisting of underplated basement and sedimentary slices related to the Valaisan subduction [33]. After the onset of continental collision, E-W extension took place along major ductile displacement zones; late folding overprinted and steepened the previous structures. The latest structures are brittle normal faults cross-cutting all the previous structures (e.g. the Forcola fault), and may be coeval with displacements along the
Engadine line and the Iorio-Tonale line, which corresponds to the late stage of the Insubric line [34].

In brief, the regional geological setting of the San Giacomo Valley is characterized by the emplacement of sub-horizontal gneissic bodies ("Tambò" and "Suretta" units), emplaced towards East, and separated by a metasedimentary cover unit, called "Spluga Syncline". The tectonic contact between the two main nappes gently dips towards NE. The Tambò and Suretta nappes form thin crystalline slivers, each about $3.5 \mathrm{~km}$ thick, essentially composed of polycyclic and poly-metamorphic basement of paragneiss; thin layers of amphibolite and orthogneiss are intercalated within the paragneiss. The lithological features of basements are almost similar. The basement of both nappes is unconformably overlain by a Permo-Mesozoic sedimentary cover, which shows a typical stratigraphy of internal Brianconnais sediments [35]. The Permo-Mesozoic cover, from older to younger sediments, is constituted of: conglomerates with quartz pebbles and albitebearing quartzites, which probably formed from Permian volcanodetritic sediments [36]. The Mesozoic cover consists of pure quartzites in the Suretta nappe and impure quartzites in the Tambò nappe, dolomitic marbles, marbles and schists. The Tambò cover unit, called Spluga Syncline, shows important deformation and thickness variations: from a few metres up to several hundred metres in thickness. The Alpine metamorphic grade increases from the top of the Suretta nappe to the bottom of the Tambò nappe and from the North to the South of nappes from greenschist facies to amphibolite facies [37].

In the San Giacomo Valley main structural alignments show the following directions: WNW-ESE, NW-SE, NE-SW and NS. The first system seems to be related to the regional orientation of the Insubric Line, whilst the second one has the features of the Forcola Line. The NE-SW system is related to the Engadine Line and is characterized by shear component of movements, which are frequently underlined by movement streaks. The last system, parallel to the valley, is not directly connected to any tectonic line of regional significance, but it is represented by a bundle of persistent fractures, including both fractures formed in the postglacial age, and shear joints, probably attributable to pre-existing tectonic lines, along which the pre-glacial valley developed. In the study area, beyond the main mentioned systems, many other local discontinuities sometimes occur; they have been locally described during the geomechanical surveys.

\section{Local rock mass properties}

In the San Giacomo Valley, geomechanical surveys have been carried out, during several field campaigns, in 97 different sites, mainly located on the left side of the Liro Stream; 78 sampling points involve the Tambò basement, 7 the Spluga Syncline, and 12 the Suretta basement. As shown in Fig. 1b, the measurement points are very scattered, because they are strongly affected by the position and accessibility of the outcropping rock masses.

Detailed geomechanical field surveys have been performed according to the International Society of Rock Mechanics (ISRM) suggested methods [38], allowing the characterization of each investigated rock mass, its intact rock and discontinuities, in terms of: number of main joint sets, their representative orientation, vertical and horizontal intercepts, average set spacing, persistence, aperture, degree of weathering, moisture conditions, roughness and joint wall compression strength coefficients, presence and nature of infill. From the collected data, rock mass quality indexes, such as the RMR and the Geological Strength Index [39], have been evaluated.

The RMR defines the geomechanical quality of a rock mass as the sum of five rates referred to the following rock and rock mass 


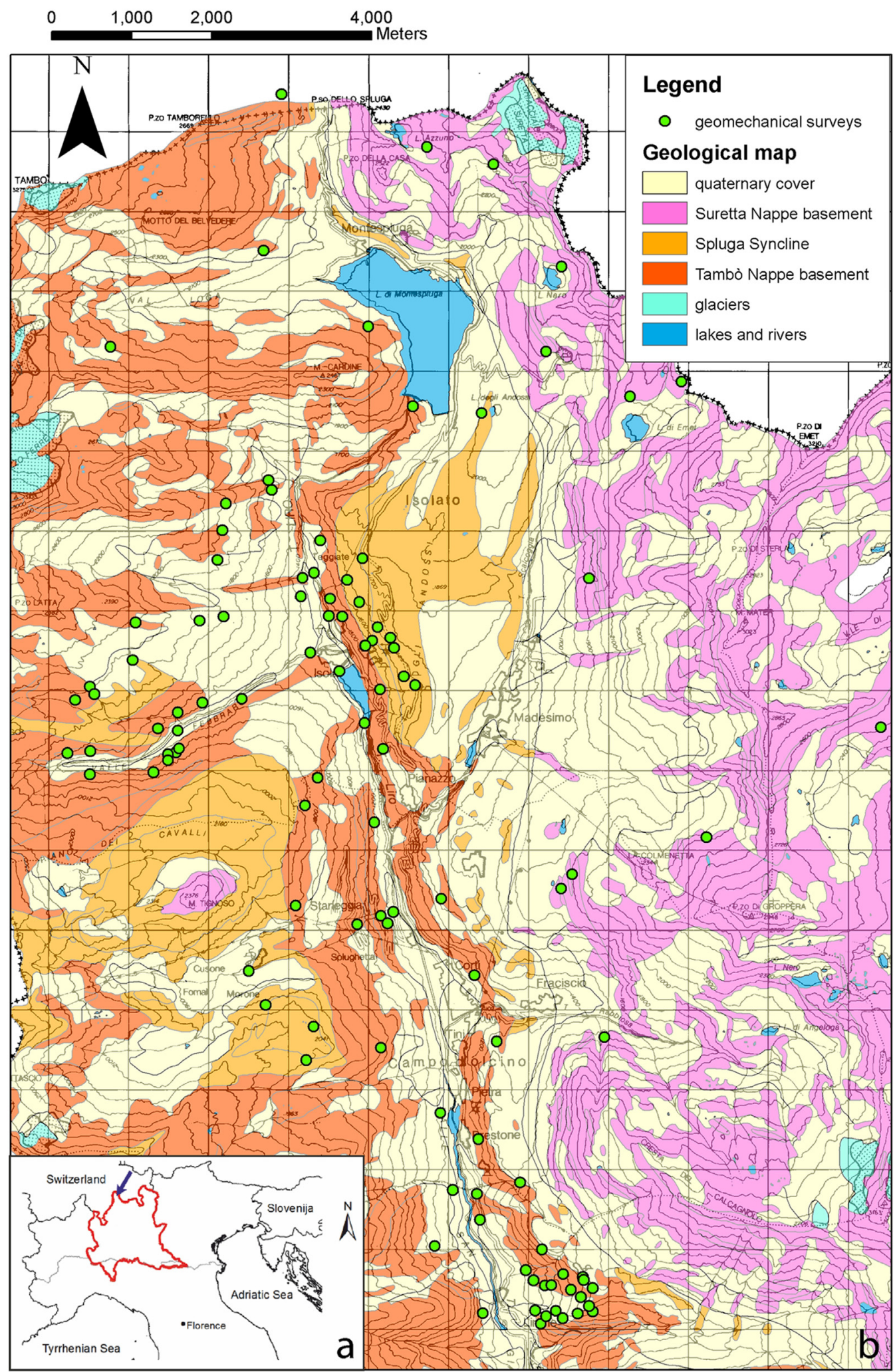

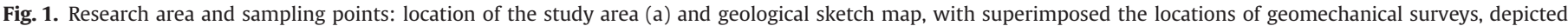
with circles (b).

parameters: the uniaxial compression strength of rock matrix, the Rock Quality Designation (RQD), the discontinuity spacing, the condition of discontinuities and the water presence. The resulting RMR value, which can range from 0 to 100 , increases as the rock mass quality gets better; indeed the values have been classified in five classes of quality: poor (if $R M R$ values are between 0 and 20), scarce $(21<R M R<40)$, fair $(41<R M R<60)$, good $(61<R M R<$ $80)$ and very good quality $(R M R>81)$.

The use of the RMR index as a unique regionalized variable, as usually done [24-31], can constitute a conceptual mistake, because the RMR considers parameters with different origin, assigning them different weights, and so each parameter is not considered in 
an independent way. It is worth noting that, considering only the final RMR value and not the individual parameters, geostatistical analysis becomes easier and faster; this approach could be reasonable to assess the rock mass quality in a wide area and especially to individuate the critical sites without understanding why low RMR values occur, i.e. what is the parameter that renders the RMR so low. For the sake of clarity, before describing the RMR resulting values, some details on the distribution of each parameter involved in the RMR calculation have been outlined.

\subsection{Uniaxial compressive strength of the rock matrix}

The first RMR parameter has been defined, where possible, considering the joint compressive strength (JCS), as indicated in the ISRM suggested method [38]. The JCS have been measured on abraded discontinuities, with Joint Roughness Coefficient (JRC) smaller than 9, using the Schmidt hammer, and correcting the rebound values on the basis of the hammer orientation. The calculation of JCS has been performed by applying the following formula:

$\mathrm{JCS}=10^{(0.00088 \gamma R+1.01)}$

where $\gamma$ is the weight unit of rock material (expressed in $\mathrm{kN} / \mathrm{m}^{3}$ ) and $R$ is the representative rebound, i.e. the mean of the five higher measured values on a set of 10 measures for each tested discontinuity.

The results (Fig. 2) show a high variability of JCS values, which are very scattered and range from 35 to $216 \mathrm{MPa}$, although the outcropping rocks are almost all paragneiss. It follows that in the studied area, the lithology does not seem to play a significant control on the JCS values, excepting the amphibolite lenses which always give high JCS values, which however are aligned and not higher than the maximum paragneiss value. As a consequence, in this area, the estimation of the JCS values, in each point of the domain, constrained by the outcropping lithology, should lead to meaningless results, also due to the lack of significant number of sampling points for the lithologies, such as amphibolite and quartzite, which outcrop only sporadically, in small lenses or in veins and so in very localized zones.

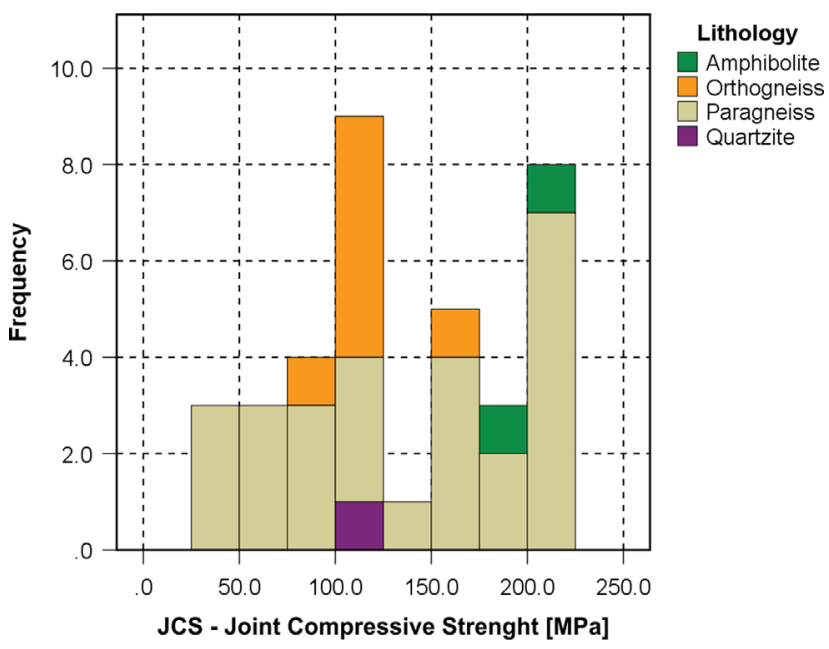

Fig. 2. Joint wall compressive strenght data: frequency distribution histogram of the JCS, which is the first parameter used to calculate the Rock Mass Rating index; different colours represent diverse lithologies.

\subsection{Rock quality designation (RQD)}

The second parameter used to calculate RMR has been indirectly derived, due to the lack of cores referred to in the survey location. Palmstrom [40] has suggested that, when cores are unavailable, the RQD may be estimated from the number of joints per unit of volume, in which the number of discontinuities per metre for each joint is added. The conversion formula for clay-free rock masses is as follows:

$\mathrm{RQD}=115-3.3 \mathrm{Jv}$

where Jv is the Volumetric Joint Count, which represents the total number of joints within a unit of volume of rock mass and can be derived from the average spacing of each discontinuity set:

$\mathrm{Jv}=100 / S_{K 1}+100 / S_{K 2}+\cdots+100 / S_{K n}$

where $S$ is the joint spacing, in centimetres, for each joint set $K n$. Since Jv is based on joint measurements of spacings or frequencies, it can be easily calculated.

In the study area, Jv values range from 6.7 to 66.6 fractures $/ \mathrm{m}^{3}$, with a mean value of 25.3 fractures $/ \mathrm{m}^{3}$, and a standard deviation of 13.3; the frequency distribution is clearly uni-modal (Fig. 3a), with a positive asymmetry. Also for Jv it is possible to note that the lithology does not play a key role on the fracturing density, being the values very scattered independently of the lithology, with the exception of orthogneiss, which always shows a low fracturing degree.

The Jv has already been estimated, as an independent variable, in the whole studied area, using geostatistical techniques, both on $2 \mathrm{D}$ and 3D grids $[41,42]$.

\subsection{Spacing of discontinuities}

The spacing values have been directly measured for each discontinuity set during geomechanical surveys. The mean values, which have been calculated for each geomechanical station, have been reported in Fig. 3b and range from 9.9 to $78.7 \mathrm{~cm}$. Also in this case the values of mean spacings are very scattered, and are irrespective of the outcropping lithology.

\subsection{Conditions of discontinuities}

This parameter includes the following properties, which have been determined for each set:

persistence: it describes the discontinuity length; almost all the examined rock masses (86\%) are characterized by an average lateral persistence, that is between $50 \%$ and $90 \%$ (i.e. between 3 and $10 \mathrm{~m}$ ) of the outcropping rock mass.

aperture: it has been measured or estimated using ISRM classes [38]. Where the aperture class has been only estimated, in order to pass from a qualitative to a quantitative description of apertures, the maximum value of each class has been considered. This assumption has led to a poly-modal, discrete distribution (Fig. 4a), in which the highest peak is however recognizable, and so the maximum frequency, which is related to the smallest class value of the histogram. The mean aperture values range from 0.4 to $105 \mathrm{~mm}$, and obviously no correlation exists with the lithology.

roughness of surfaces: the Joint Roughness Coefficient (JRC) is probably the most commonly used measure of roughness of rock joint surfaces. The JRC has been evaluated by visual comparison of measured profiles against a set of standard JRC profiles produced by Barton and Choubey [43]. The mean JRC values for each investigated rock masses are between 4 and 14 (Fig. 4b). 


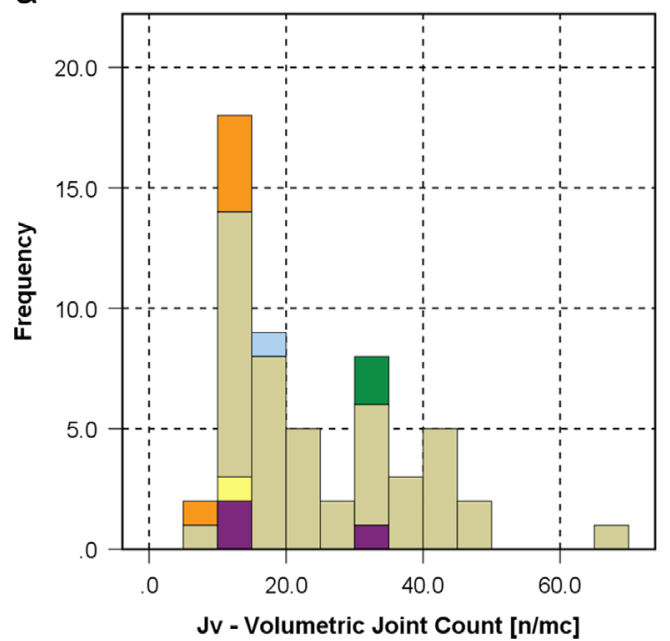

b

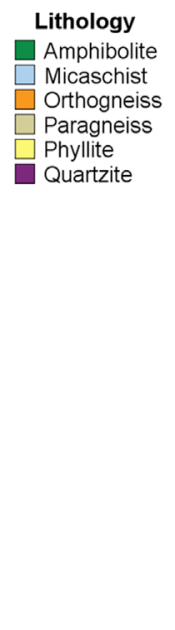

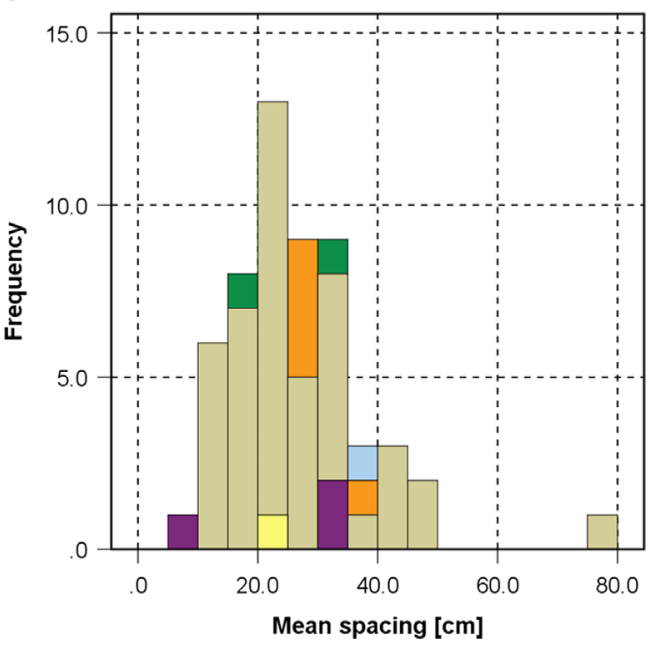

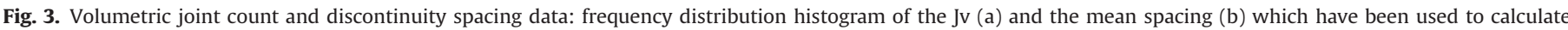
respectively the second and the third Rock Mass Rating parameter; different colours represent diverse lithologies.

a

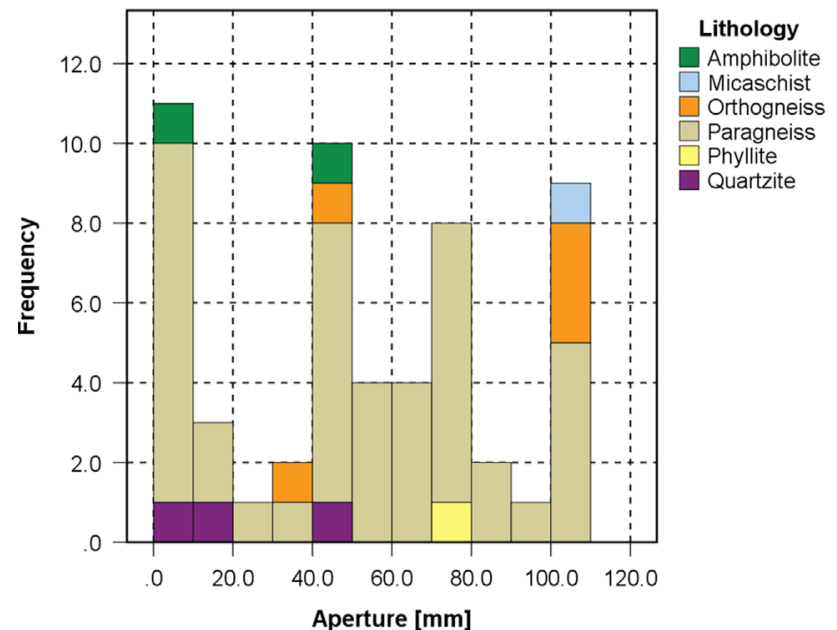

b

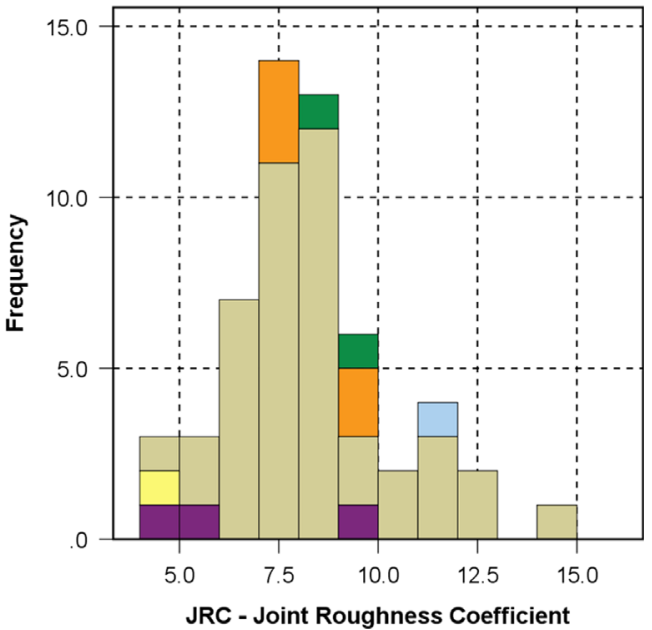

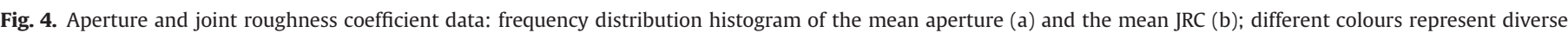
lithologies.

presence and kind of infilling: the infilling is absent in almost $90 \%$ of the investigated sets.

weathering condition: the rock masses show a low alteration degree, in particular it is frequent to observe slightly weathered discontinuities, which are bleached only on the surface.

\subsection{Groundwater conditions}

The fifth parameter of the RMR classification takes into account the occurrence of water along discontinuities; different values have been assigned on the basis of general moisture conditions of the rock mass, which can be: completely dry (observed in 64\% of surveyed sites), damp (24\%), wet (11\%), dripping (never) or flowing (1\%).

The sum of these five parameters leads to the Rock Mass Rating value, which describes the global quality index of the rock mass. From the collected data, some general considerations can be outlined, with the aim to describe analogies and differences in the investigated rock masses, especially about their quality. The examined rock masses, belonging to Tambò and Suretta basement units, show a similar behaviour. Joint orientations and properties are quite similar, and the small variability in lithological characteristics does not significantly control the discrepancy in rock mass quality [44]. Rock masses of the meta-sedimentary cover, the Spluga Syncline, show a general greater state of deformation. However, for all the lithological and structural units, some common properties have been observed: the water is mostly absent, discontinuities are slightly weathered, without infillings and with a medium persistency. The other parameters, i.e. JCS, JRC, aperture, spacing, Jv and consequently RQD, show a great variability, which does not seem to be directly related to the lithology. Indeed, in spite of this lithological variability should obviously be responsible for variations in rock mass quality; it is worth noting that all RMR values are contained in only two classes, irrespective of the lithology (Fig. 5): they range from 45 to 77, half of them belong to the "fair quality" class $(41<\mathrm{RMR}<60$ ), while the other half belong to the "good quality" class $(61<\mathrm{RMR}<80)$; most RMR values are included between 50 and 70 .

It can be stated that in the study area the geomechanical quality of rock masses (expressed by the RMR) mainly depends on the geometrical features which show greater variability, i.e. 
spacing and correlated values of Jv and RQD [45], JCS and conditions of discontinuities (with particular reference to aperture and roughness). These properties, which are related to tectonic actions, could be considered as regionalized variables, as RMR. Actually, the RMR depends on the geological and structural history of the rock mass, but it describes the quality of the rock mass nowadays, resulting from all the involved geological events. The RMR is a global property of rock masses, depending on all its fractures, despite of their formation mechanism. Therefore the statistical population of RMR is represented from all the rock masses outcropping in the San Giacomo Valley. The homogeneity of the data samples has been guaranteed, because the same support (a scanline $20 \mathrm{~m}$ long) has been used in all the geomechanical surveys, with a surveyed height of about $2 \mathrm{~m}$.

\section{Geostatistical analysis}

Geostatistics allows estimating the values of regionalized variables in un-sampled points, capturing the spatial correlation among data, based on the fact that the data sourced from closer locations tend to be

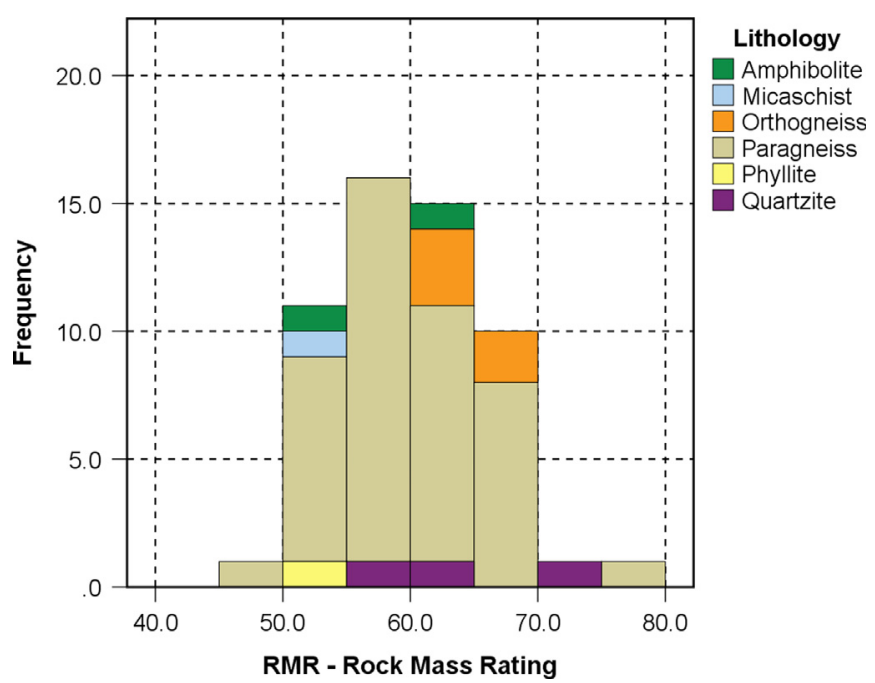

Fig. 5. Rock Mass Rating values: frequency distribution histogram of the Rock Mass Rating; different colours represent diverse lithologies.

a

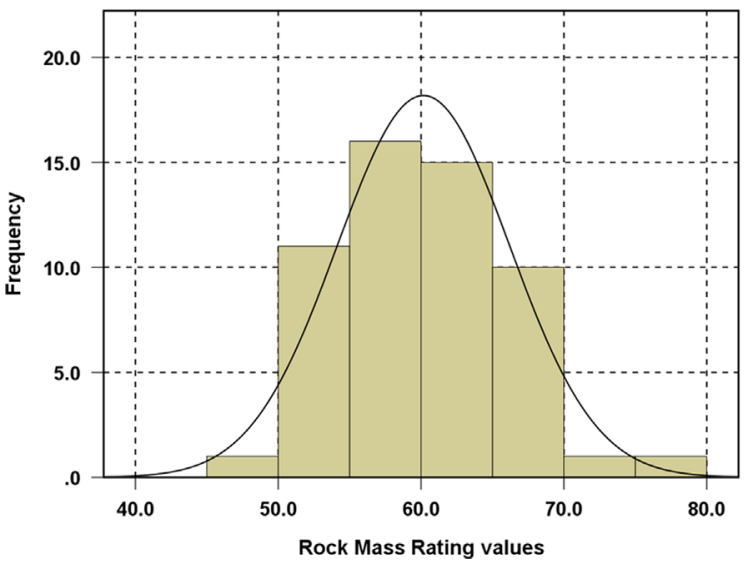

more similar than those far apart. Geostatistics provides an unbiased estimation, with uncertain quantification.

Geostatistical approach has been already used several times in rock mass characterization [7-31]. In this paper, geostatistical analysis has been performed in order to reconstruct the values of RMR in an area with an extent of approximately $200 \mathrm{~km}^{2}$, from superficial field data. The geostatistical study has been performed with the RMR index as regionalized variable and has been developed by the following phases: exploratory spatial data analysis, variography, prediction and finally validation.

\subsection{Exploratory spatial data analysis}

First of all, the statistical parameters of RMR have been computed. The RMR index has been evaluated in 55 different locations, along the San Giacomo Valley. RMR values range from 45 to 77 , the mean is 60.6 , with a standard deviation of 6 . The frequency distribution seems to be Gaussian, indeed it is clearly a unimodal distribution, without a significant asymmetry (Fig. 6a), being both skewness and kurtosis close to zero.

Since many geostatistical techniques are more reliable if the variable of interest has a standard Gaussian distribution, it is necessary to verify if the variable has a normal distribution and if not the transformation of data into a standard Gaussian one is essential. It is rare in the modern geostatistics to consider untransformed data. The use of Gaussian technique requires a prior Gaussian transformation of data and the reconstruction of semivariogram model on these transformed data. This transformation has some important advantages: the difference between extreme values is dampened and the theoretical sill should be close to the unit [46]. Furthermore systematic trends should be removed from the variable prior to transformation and semivariogram calculation.

The problem is that the most common statistical tests, used to verify if the univariate distribution of the data is Gaussian, are designed on the assumption that the observations are independent and identically distributed. In geostatistical applications, however, this is not usually the case: if the covariance structure has a range greater than the minimum distance between observations, the data are correlated and the standard tests cannot be applied to the probability density function (pdf) or cumulative probability function (cdf) estimated directly from the data. The problem with correlated data arises not from the correlation per se, but from cases in which correlated data are clustered rather than being located on a regular grid [47]. When preferential sampling occurs, observations that are close together provide

b

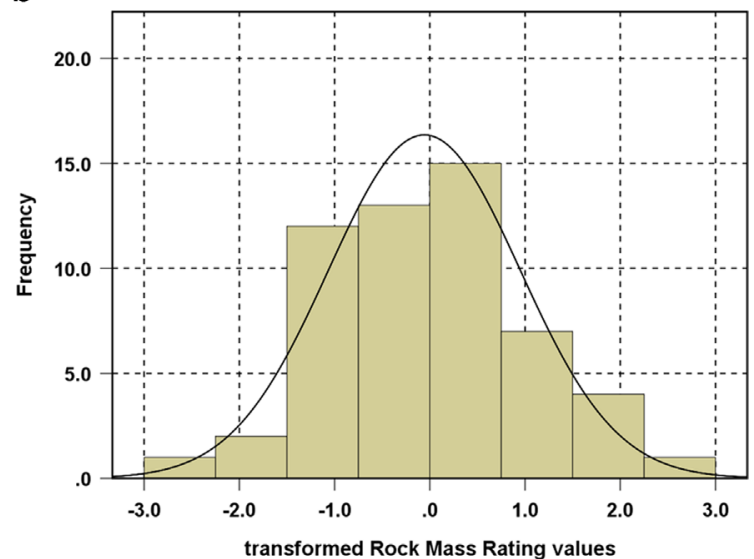

Fig. 6. Rock Mass Rating values: frequency distribution histogram of raw (a) and transformed (b) data, with superimposed the Gaussian distribution (solid line). 
partially redundant information that must be taken into account in calculating pdf or cdf. Actually, it is difficult and often impossible to sample geological data using a regular grid; therefore the occurrence of preferential sampling is very frequent. For instance, in this case study, the sampling locations are dependent on the outcrop positions and their accessibility; hence they are not disposed on a regular grid.

The preferential sampling could lead to the presence of spatial clusters, and subsequent biases. When the sampling is clustered, unbiased estimates of pdf or cdf must first be obtained, by declustering, then normality tests can be applied. In this case study, the analysis of the spatial disposition of 55 considered data locations has been performed through the nearest neighbour index, which uses the distance between each point and its closest neighbouring point to determine if the point pattern is random, regular or clustered. The nearest neighbour index is expressed by the average distance between each point and its nearest neighbours, divided by the expected distance (i.e. the average distance between neighbours in a hypothetical random distribution). If the index is less than 1, the pattern exhibits clustering; if the index is greater than 1 , the trend is towards dispersion or competition. In this case study the index is equal to 1 , with a standard deviation of 0.03 , showing that the pattern of sampling locations is neither clustered nor dispersed. Therefore the data de-clustering is not necessary and has not been performed.

The normality of RMR distribution has been verified using various graphical and statistical tests, such as Shapiro-Wilk test [48] and Kolmogorov-Smirnov test with Lilliefors correction [49]; hence the Gaussian distribution of RMR has been confirmed with a significance level of $1 \%$.

Since the standard Gaussian distribution, with mean and variance equal to 0 and 1, respectively, is required, the Gaussian distribution of RMR has been transformed in a standard one (Fig. 6b), through a process called Gaussian anamorphosis.

As many geostatistical methods are based on the spatial stationarity property, the absence of systematic trends has to be verified. The study of trends, which has been carried out representing the magnitude of variable along different directions in the space, has allowed us to confirm the stationarity hypothesis of RMR in the studied domain. In particular the absence of trend allows applying the kriging without trend, which accounts for local fluctuations of the mean limiting the domain of stationarity of the mean to the local neighbourhood centred on the location under estimation [50].

\subsection{Variography}

The variography is based on the modelling of semivariogram, which is the tool that permits to individuate the occurrence of some spatial structure in the dataset. The construction of semivariogram, that is the mathematical model which captures the spatial correlation among data, is a very important step in any geostatistical analysis. The semivariogram is a measure of variability, it increases as samples become more dissimilar. The variogram is defined as the expected value of a squared difference [51]:

$\left.2 \gamma(h)=\operatorname{Var}[Z(x)-Z(x+h)]=E\{Z(x)-Z(x+h)]^{2}\right\}$

where $Z$ is a stationary random function with known mean $m$ and variance $\sigma^{2}$, which is independent of location, so $m(x)=m$ and $\sigma^{2}(x)=\sigma^{2}$ for all locations $x$ in the study area, therefore the variogram function depends only on the distance $h$ and so the intrinsic hypothesis occurs.

The variogram is a graph that can be obtained by plotting the distance among sampling points (called lag) on $x$-axis, versus the associated variance, on the $y$-axis. The variogram therefore is the expected squared difference between two data values separated by a distance vector. The semivariogram $\gamma(h)$ is one half of variogram $2 \gamma(h)$, to avoid excessive jargon in this paper we simply refer to it with the term variogram.

If a variable is correlated, initially the variogram increases and then becomes stable beyond a distance $h$ called range. Beyond this distance, the mean square deviation between two quantities $Y(u)$ and $Y(u+h)$ no longer depends on the distance $h$ between them and the two quantities are no longer correlated. When the range is different in some directions of space, the examined regionalized variable exhibits a geometric anisotropic structure. The range corresponds to a variance value called sill, which corresponds to zero correlation. Briefly the variogram quantifies the distance (range) at which samples become uncorrelated from each other, giving an idea of the best and the worst spatial correlation directions among the data. The former occurs where the range is maximum, the latter has been assumed perpendicular to the maximum correlation direction.

The computation of the variogram is based on the Mean Ergodic Hypothesis [52] that permits the substitution of the stochastic mean value with the mean value of all the couples of measurement points that are approximately $h$ distance apart. This implies that the process is regular or statistically homogeneous to ensure that, from a unique realization of the process, there is a representation of all possible values that the process can attain. Actually, the mean value of the regionalized variable does not depend on its spatial position, but on the distance from the realizations.

A random function is mean-ergodic if the process has finite variance: the process may be assumed to be distribution-ergodic if the indicator covariance function tends to zero for a distance known as the (practical) range of the covariance, and this distance is much smaller than the maximum distance inside the considered domain. It follows that the semivariogram must reach a sill, within a finite distance [47]. This condition can be used to check experimentally the distribution-ergodic hypothesis. In this case study, the experimental variograms (Table 1) do not have a drift effect (i.e. they are not monotone ascending), but present a sill; hence the ergodic hypothesis is respected.

In practice, the process is not observed over an infinite domain but over a finite domain of interest. The ergodicity explains the inevitable fluctuations of statistics and their consequences on modelling. These ergodic fluctuations are due to the limited, finite extent of the spatial domain being simulated. Simulation on an infinitely large domain will result in statistics of realization that exactly match the model statistics. Therefore, when simulating on a finite domain, some statistics have smaller variations than other. Ergodicity therefore plays an important role in both the estimation of model parameters as well as their simulation [53]. It is typically advised in traditional geostatistical practice not to use any lag distance information beyond $1 / 2$ the size of the field, since they are not reliable (not enough samples to provide a reliable variogram), and this statement has been observed in this work.

Variography has been applied here to recognize the RMR spatial distribution of the examined rock masses. An interpretation of variograms able to give a complete answer to the geological phenomena occurred in the studied area is truly difficult and complex, being San Giacomo Valley located in an alpine dynamic context, which does not have a simple geological history, with the superimposition of numerous short time events with major processes acting on geological time scales. However it is easy to understand that geological characteristics that have been formed in a slow and steady geological environment are better correlated to each other than if they had been results of an often abruptly changing geological process [54], such as in the research area. 
Table 1

Variogram of Rock Mass Rating transformed data: on the left the variograms obtained from the bi-dimensional approach, are depicted, while on the right those from the almost three-dimensional one. Lag distance increases from the top to the bottom.

\begin{tabular}{ll}
\hline RMR & \\
\hline $2 \mathrm{D}$ & Almost 3D \\
\hline
\end{tabular}

Lag $=250$ metres
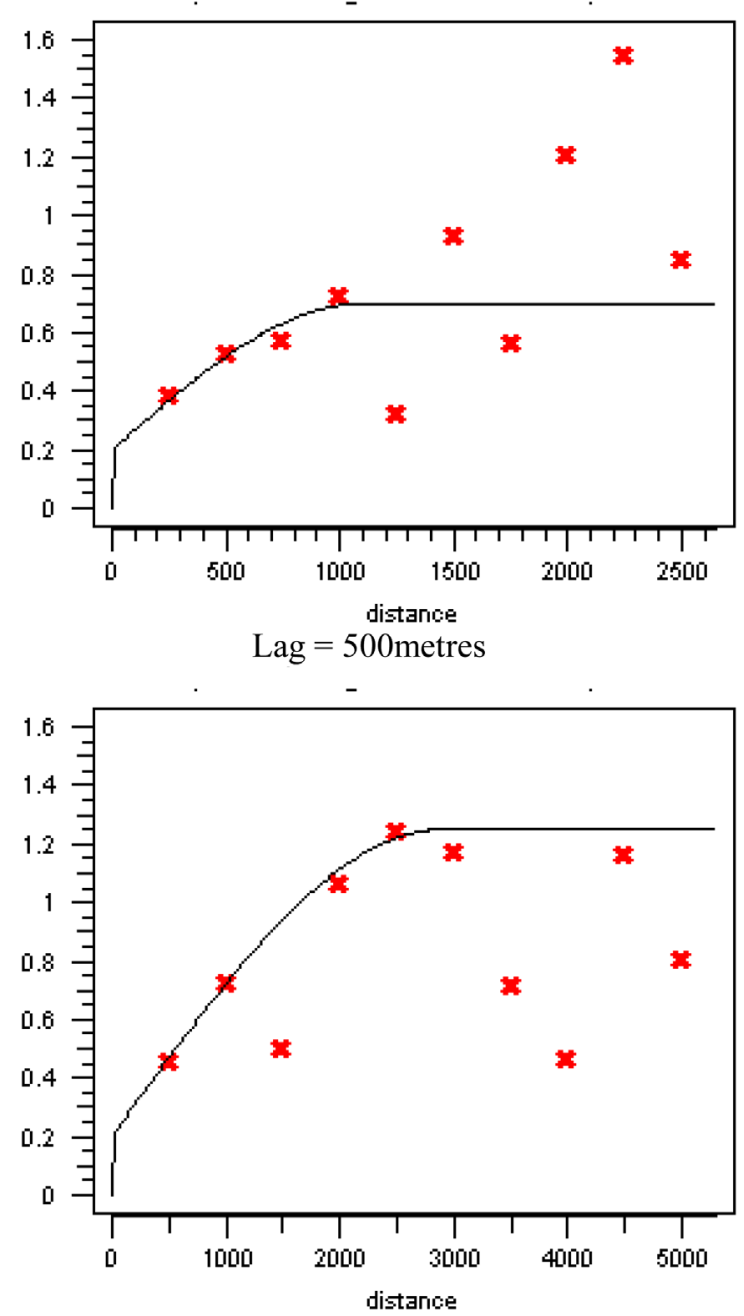

Lag $=1000$ metres

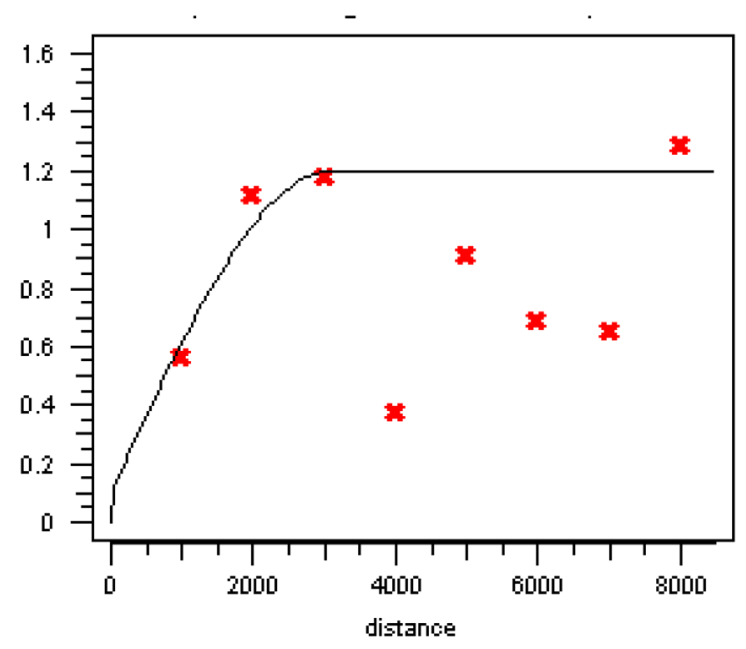

Lag $=250$ metres

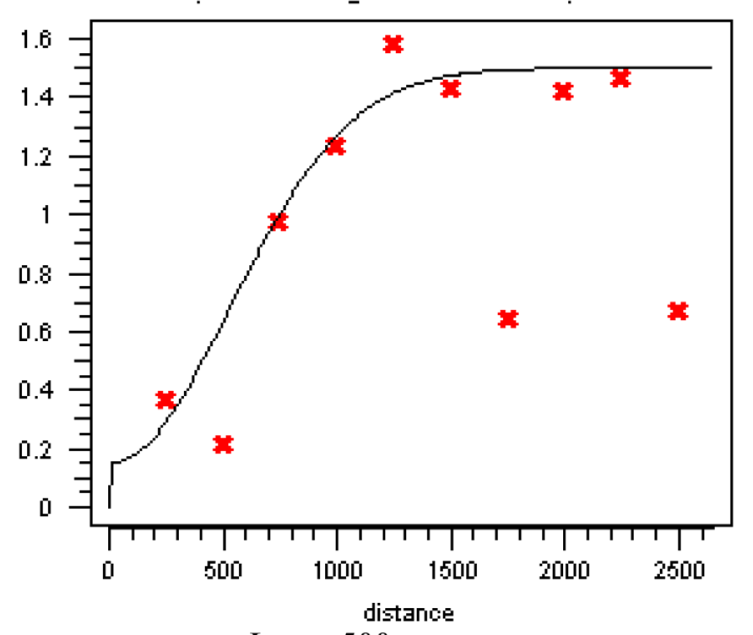

Lag $=500$ metres

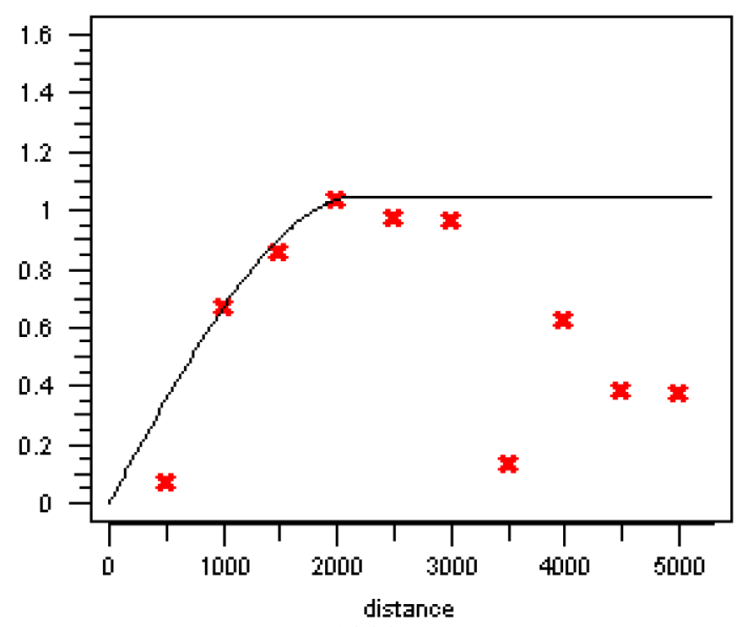

Lag $=1000$ metres

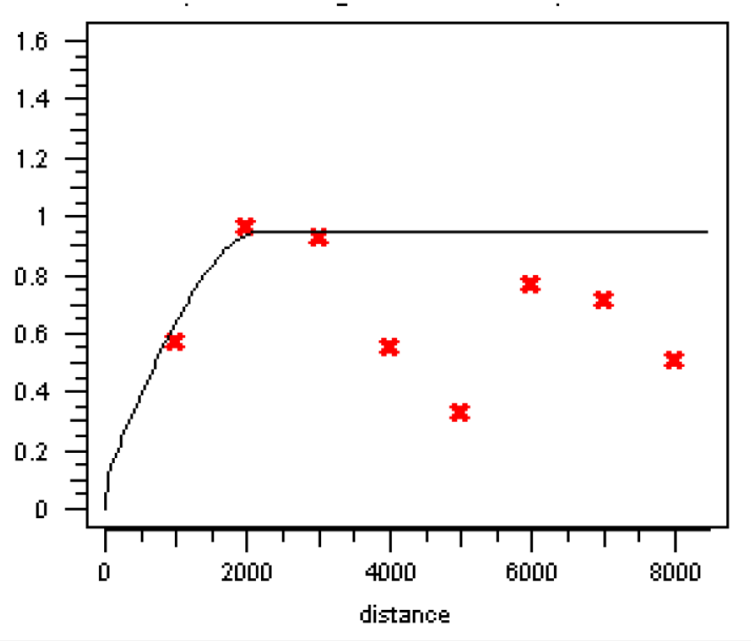


The variogram has been constructed using transformed data, with the support of the Stanford Geostatistical Modelling Software (SGeMS) [55]. The correlation structures of RMR have been investigated at different scale and the possible occurrence of anisotropies has been taken into account.

First of all an omni-directional variogram, which relates the distance among pairs of sampling points with their variance, has been constructed in order to individuate if a correlation of the variable in the research area exists. The presence of any preferential correlation direction has been first sought graphically using a 2D variogram map, which is a plot of experimental variogram values in a coordinate system $\left(h_{x} ; h_{y}\right)$ with the centre of the map corresponding to the variogram at lag $(0 ; 0)[50]$. A more detailed research of maximum correlation direction has been conducted through the construction of several directional variograms, with a variation direction of $45^{\circ}$ and an angular tolerance of $22.5^{\circ}$.

Three experimental variograms have been constructed at different scales, varying the lag distance from 250 to $1000 \mathrm{~m}$, and therefore increasing the maximum distance under study. The lag tolerance has been assumed equal to the half of lag distance.

A good regionalized variable should show an invariance of scale: variograms should not depict important changes varying the scale, the structure and the maximum correlation direction should remain approximately the same [41], although small heterogeneities, which are neglected in the variograms with large lag, could be better highlighted in the variograms created with small lag.

Experimental variograms have been determined using both a classical 2D approach and an almost 3D one: in the former the distance among pairs of samples depends only on latitude and longitude, in the latter, altitude also contributes to the distance and it should play an important role where elevation gradients are worthy of note, such as in the study area. When the approach changes, the maximum correlation direction becomes slightly different: in the 2D approach it is towards NNE $\left(22.5^{\circ}-202.5^{\circ}\right)$, whist in almost 3D one it has a dip direction toward NE $\left(45^{\circ}\right)$ and dip of about $20^{\circ}$, this orientation is in accordance with the discontinuity set developed parallel to the regional foliation, which dips towards East with a low dip angle, and therefore has a remarkable geological significance. Nevertheless, there are some analogies between the two different approaches, withthe variable under study being the same. First of all, almost all the experimental variograms are better fitted by a spherical theoretical model; therefore variance values increase with the lag; this indicates that the variability of RMR increases as the distance $h$ among sampling points grows and so that RMR is a regionalized variable.

The variogram models do not tend to zero when $h$ is zero; this discontinuity of variogram at the origin, which corresponds to the short scale variability, is called nugget effect and can be due to local

Table 2

Variogram model parameters: the summary of values obtained by modelling experimental variograms.

\begin{tabular}{lccc}
\hline & Lag= 250 $\mathbf{~}$ & $\mathbf{L a g}=\mathbf{5 0 0} \mathbf{~}$ & $\mathbf{L a g}=\mathbf{1 0 0 0} \mathbf{~}$ \\
\hline 2D approach & 0.2 & 0.2 & \\
Nugget effect & 0.7 & 1.25 & 0.1 \\
Sill & 1100 & 2900 & 1.2 \\
Maximum range (m) & 400 & 300 & 3100 \\
Minimum range (m) & & 0 & 200 \\
Almost 3D approach & 0.15 & 1.05 & 0.1 \\
Nugget effect & 1.5 & 2200 & 0.95 \\
Sill & 1300 & 700 & 2200 \\
Maximum range (m) & 700 & & 200 \\
Minimum range (m) & &
\end{tabular}

heterogeneities of the geology structures, with correlation ranges shorter than the sampling resolution, or to measurements errors; it is worth noting that the nugget effect of all variograms is close to zero and it is bigger in the 2D approach, this could be related to the fact that altitude of sampling point is neglected in the 2D approach. Actually such small nugget effect is also because the support of the measure (equal to $20 \mathrm{~m}$ ) is significantly smaller than the range.

Regarding the sill, its maximum admitted value is a debated topic, which has been considered by several authors [46,50,56,57]; some scientists support that the maximum sill value should be equal to the variance, and thus to the unit in transformed variables, while others admitted a sill value bigger than the variance. In this geostatistical analysis model with a maximum sill both equal to sample variance and bigger than the sample variance has been constructed. Since the validation shows that, in this case, the sill greater than the unit provides the best results, in the following phases only the model with the sill bigger than the sample variance has been considered and described. The experimental variograms show that generally the sill decreases when lag distance increases, because the small heterogeneities are neglected and consequently the variance reduces. Finally, respect the range, it is possible to notice that maximum range increases with lag distance, because the distance considered is longer, while minimum range decreases.

Experimental and derived theoretical variograms, along the maximum correlation direction, obtained using different lag sizes, are shown in Table 1, while Table 2 reports the parameters used to create the variogram models.

\subsection{Prediction}

The prediction allows us to estimate RMR values in a whole domain. In the 2D approach, the prediction has been carried out using a grid which represents the study area in terms of longitude and latitude, while in the 3D model altitude has also been considered. Since borehole data are not available, the RMR index has been estimated only on the topographic surface and not in depth. The used grid is defined by regular square or cubic cells, $100 \mathrm{~m}$ long for each side.

The parameters of the described theoretical variograms have been employed for the spatial interpolation of RMR values, initially by means of kriging technique. Among different kriging methods, several authors $[25,27,30]$ have used indicator kriging to estimate RMR classes, but since in the study area RMR values fall within only two classes, instead of the categorical approach of indicator kriging, the numerical one of ordinary kriging has been chosen. Furthermore the indicator kriging needs an indicator transformation, which always implies a loss of information: the extra information about significant high or low values which fall within the same class is lost, actually whether a value is only a little bigger or very bigger than the chosen threshold does not play a role. The ordinary kriging, which has been already used two times in the RMR estimation [26,31], has been chosen to take in account the entire data set. The ordinary kriging is the technique that provides the Best Linear Unbiased Estimator of unknown fields [56,58], furthermore this method is a local estimator that provides the interpolation and extrapolation of the originally sparsely sampled data in the whole domain, assuming that the values are reasonably characterized by the Intrinsic Statistical Model.

Since RMR shows a strong spatial anisotropy, measurements inside an elliptic research region, with axes parallel to maximum and minimum correlation directions (individuated by the directional variograms), have been considered to perform the estimation process. In order to take into account the irregularity of data distribution, the axes of ellipse have been computed as the double of ranges. Inside each ellipse a minimum of five and a maximum of 
a

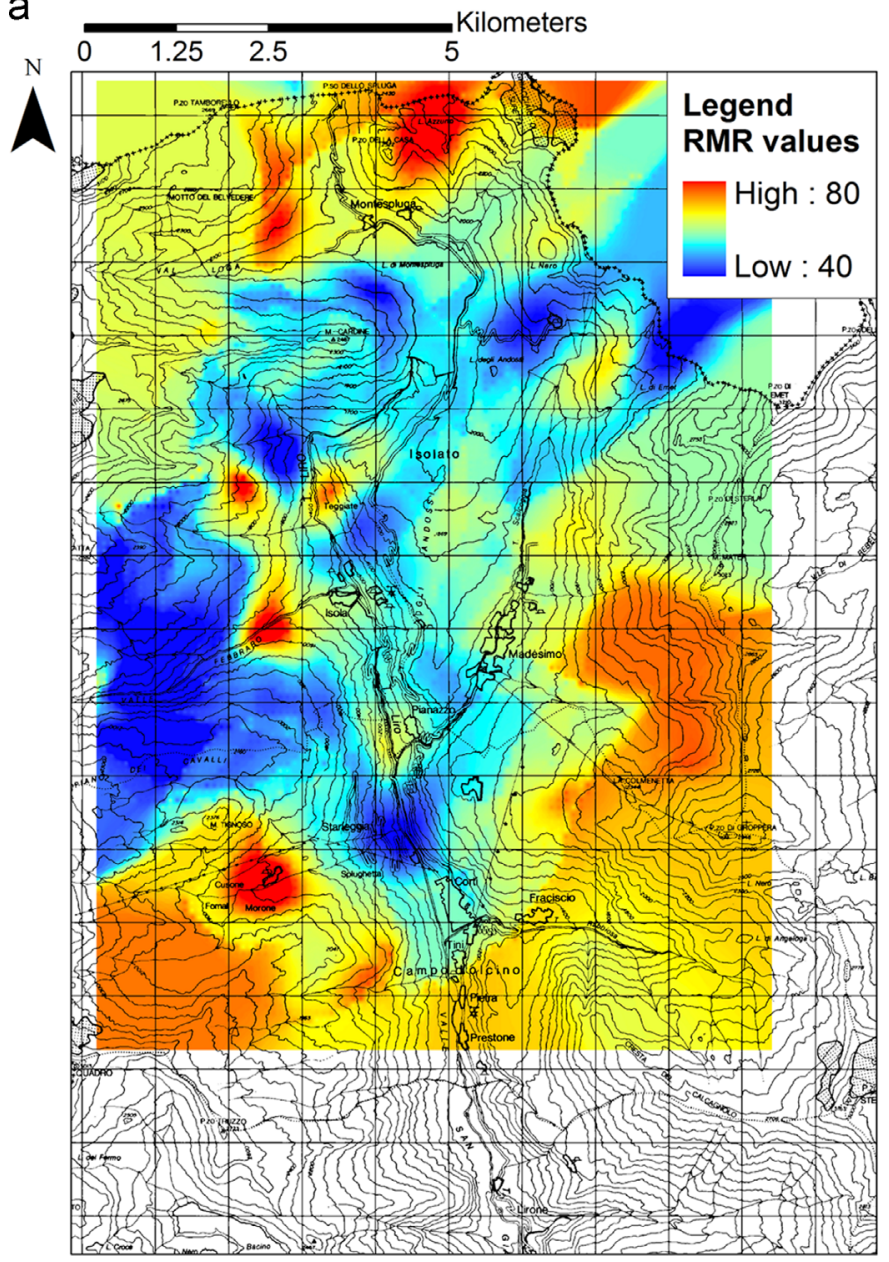

b

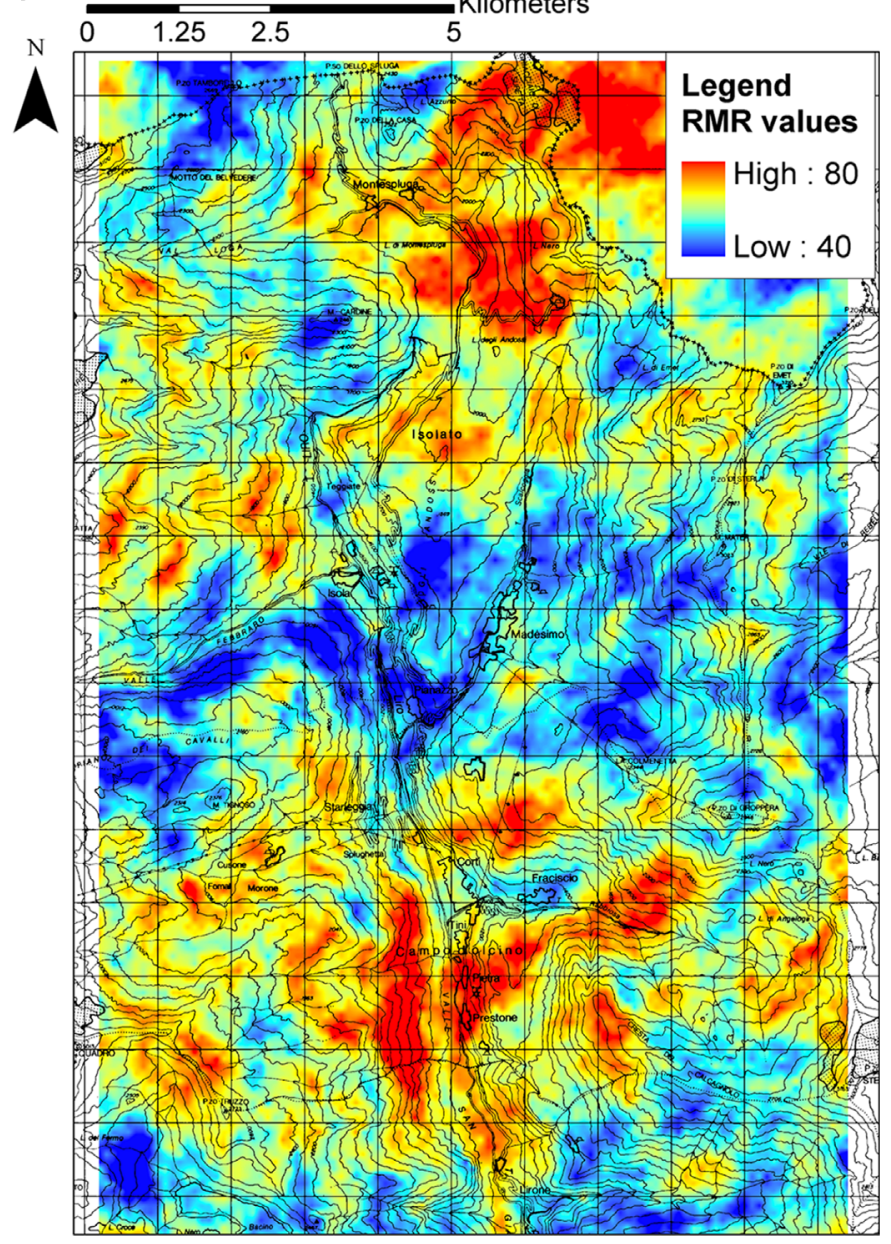

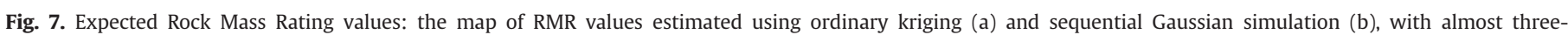
dimensional approach and medium lag.

20 data were considered; if in one research region there were less than five data the estimation was not performed, because the associated variance would be too high.

The plausibility of the interpolation models has been investigated using a cross-validation procedure, which consists of sequential estimation at each of $n$ known locations using remaining $n-1$ sampled locations of the domain. This analysis, which compares estimates and actual known sampled values, shows that the estimation method adopted tends to overestimate low values and underestimate high ones, producing a marked smoothing effect, which leads to neglect the extreme values of sample distribution and therefore does not preserve the variability of parameters under investigation. The cross-validation also shows that the smoothing effect is bigger in almost 3D models than in 2D ones. The model impacts of the smoothing effect are not very strong when the modelled parameter shows a low variability, but more variable the geology is, stronger the impacts of smoothing effect will be [54]. In an Alpine area, such as San Giacomo Valley, the smoothing effect is remarkable, therefore a method which avoids this effect is preferable. Geostatistical simulation techniques generate models without smoothing effect, taking into account the spatial variability of regionalized variable. This method does not provide the best linear unbiased estimate, but it creates realizations with the same variability as that observed in the field [6].

Gaussian sequential simulation has been performed using parameters of spatial continuity models previously defined through variogram analysis and the same grid and research ellipse as of those used in the ordinary kriging. Gaussian sequential simulation is a conditional method, which is forced to assume the measured values of the variable in the sampling points. Geostatistical simulations (or stochastic representations) can be seen as possible realizations of a spatially correlated random field, they all honour the spatial moments (mean, variance) of the field. Each simulation delivers a different realization, therefore simulations do not provide good local estimators but they are good describer of spatial uncertainty. Various realizations might initially seem to be quite different; nevertheless the variability and distribution of estimated values are very similar to those of the original data, and the smoothing effect, which has been observed using the kriging method, does not occur. Even if each simulation maintains the variability and distribution of samples, it provides a different map; hence in order to get a final map, it is necessary to calculate, in each location of the grid, a single estimated value of least squared error-type: the conditional expectation.

Fig. 7 compares the estimated RMR values obtained by the kriging approach (Fig. 7a) and sequential Gaussian simulation technique (Fig. 7b), through the almost 3D model with lag of $500 \mathrm{~m}$. Un-estimated areas (white regions in Fig. 7a) are due to elliptical research region with less than five samples. The two resulting maps are quite different and the main points discussed for the 2D prediction are still valid. Moreover the 3D kriging map appears much more continuous than the simulation map, which allows abrupt local 


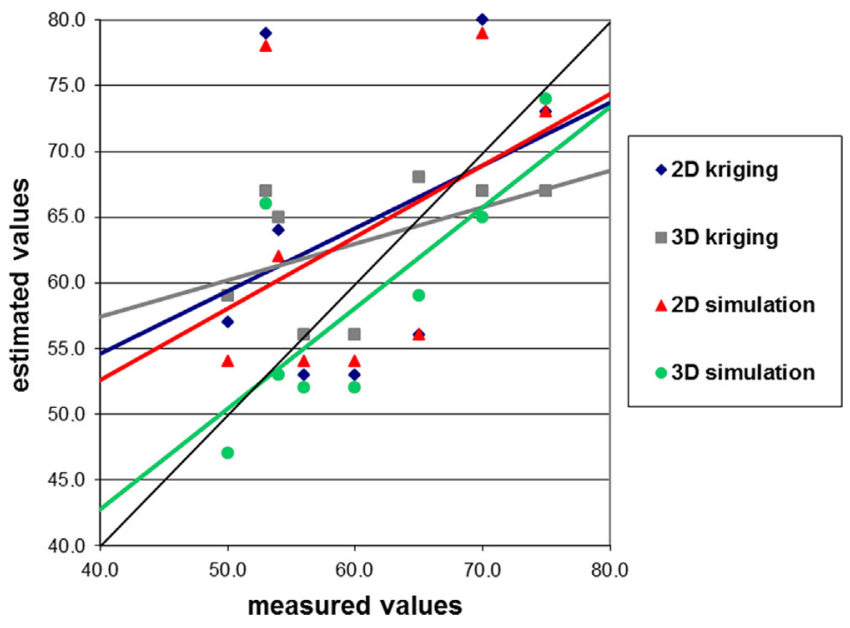

Fig. 8. Validation of results: the graph associates measured Rock Mass Rating values with the estimated ones in new sampling locations, and compares two different techniques (kriging and simulation) and approaches (bi-dimensional and almost three-dimensional).

variation; the 3D simulation seems to better count for the geological settings and topography than the 2D simulation.

The optimal number of simulations has been chosen comparing the results of 10,100 and 1000 simulations, through a validation process. In the present study the optimal number of simulations has resulted to 100 , because it provides the best compromise between the accuracy of results and the computation time.

Ordinary kriging and sequential Gaussian simulations provide quite similar outcomes for the central values of variable frequency distribution, while remarkable differences occur for the extreme values of data, indeed these values are neglected in the kriging results, while they are maintained in those coming from Gaussian simulation technique.

\subsection{Validation}

With the aim of comparing results obtained from the two different geostatistical techniques, a validation process has been performed, using an independent data set. About 10 new geomechanical surveys have been carried out in the research area to form the training point data set.

The validation process has been performed comparing measures of new sampling points with estimated values in their locations. The difference between actual and estimated values has allowed computing the following parameters (for each applied technique): mean error and its related root-mean-square, average standard error, mean standardized error and root-mean-square standardized error.

In $2 \mathrm{D}$ models the minimum mean error has been obtained by performing kriging on the longest lag distance (equal to $1000 \mathrm{~m}$ ), while the minimum standard deviation of errors comes from sequential Gaussian simulation technique also based on $1000 \mathrm{~m}$ lag distance. Generally the validation reveals a quite good agreement between measured and estimated data in new sampling locations, the results of sequential Gaussian simulation are lightly better than those obtained from ordinary kriging. Nevertheless kriging results obtained from a $2 \mathrm{D}$ grid are better than those obtained from an almost 3D one. Overall the best results come from sequential Gaussian simulation, implemented on a 3D grid, with a medium lag distance (equal to $500 \mathrm{~m}$ ), which represents the best compromise between small and big heterogeneities considered by the variogram. Actually, the almost 3D approach shows a notable difference between ordinary kriging and sequential Gaussian simulation results, being the smoothing effect of

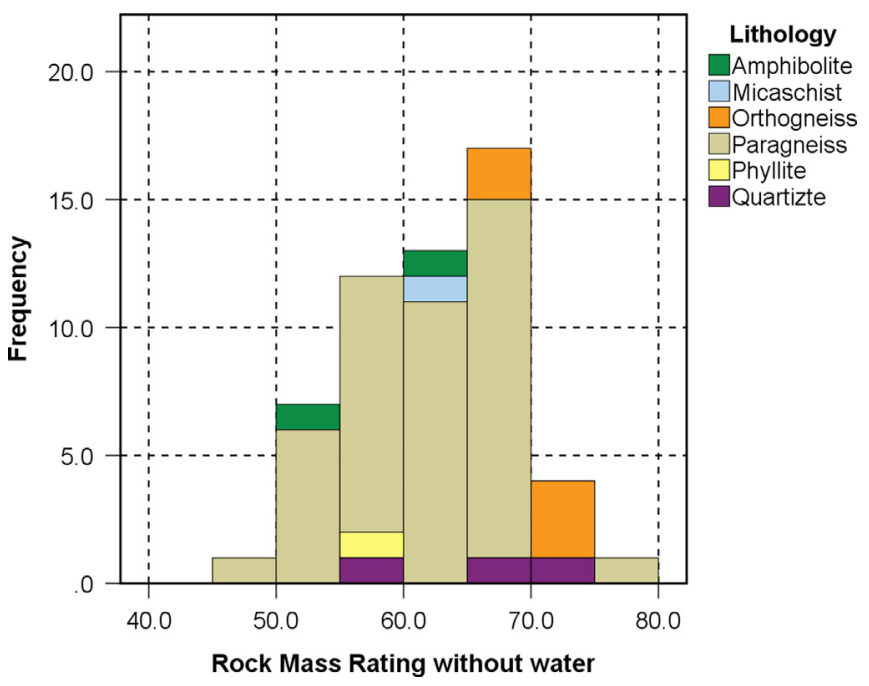

Fig. 9. Rock Mass Rating values in dry conditions: frequency distribution histogram of the Rock Mass Rating calculated with the absence of water; different colours represent diverse lithologies.

kriging very high, indeed only the central values are exactly estimated with kriging method.

A brief visual summary of the results is shown in Fig. 8, the graph relates measured and estimated values of new sampling point dataset; the bisector is the place of points where the estimated values are equal to the measurements, the line closer to the bisector, is the regression line obtained from the sequential Gaussian simulation with medium lag and 3D grid.

\section{Discussion and further improvement in prediction}

Although the validation process shows a quite good agreement between estimated and measured RMR values, the resulting maps (Fig. 7) do not seem to properly count for the geometric relation between geological and structural setting and topography. Although the almost 3D approach shows a good improvement, the topography seems to only lightly affect the map, actually in some zones the RMR values are irrespective of isohypses, although the variograms have a low angle of dip. The model might be affected by such a parameter of the RMR sum, not adequately described and poor correlated. All the RMR parameters imply geometric features, with the exception of the groundwater condition. It is worth to note that, although the RMR classification was born especially in reference to the underground rock masses involved in tunnelling, and so to the groundwater circulation, during the geomechanical surveys the external moisture conditions of rock mass are revealed; these conditions are affected by the local climatic situations of the days before the survey, especially in Alpine areas where the weather can be very changeable. Furthermore in the research area the presence of water was surveyed with very different conditions from site to site: the surveys have been carried out during different seasons and hence with several climatic and weather situations; in particular in San Giacomo Valley, as well in all Alpine valleys characterized by heavy snows in winter, the presence of water differs enormously from week to week, according to the global snow-melt regime. Consequently this parameter has not been surveyed in standard conditions and therefore could not be represented and properly introduced in the geostatistical analysis. With the aim to uniform the weight related to the presence of water, considering that $64 \%$ of the investigated rock masses were completely dry during the surveys and only $1 \%$ showed flowing condition, all RMR values 
have been computed again with the assumption that all rock masses were dry during the survey campaigns and so attributing 15 points to the last RMR parameter. The "dry RMR" values

Table 3

Variogram model parameters: summary of values obtained by modelling experimental variograms of "dry RMR" values.

\begin{tabular}{lccc}
\hline & $\mathbf{L a g}=\mathbf{2 5 0} \mathbf{~ m}$ & $\mathbf{L a g}=\mathbf{5 0 0} \mathbf{~}$ & $\mathbf{L a g}=\mathbf{1 0 0 0} \mathbf{~}$ \\
\hline Almost 3D approach & 0 & 0 & \\
Nugget effect & 1.5 & 1.2 & 1.1 \\
Sill & 2300 & 3300 & 3600 \\
Maximum range (m) & 200 & 200 & 200 \\
Minimum range (m) & & & \\
\hline
\end{tabular}

obviously are higher than the previous RMR values, although they fall again in the "fair" and "good" quality classes (Fig. 9): the mean and median values are slightly higher than those computed considering the water, whilst the extreme values, referred to dry rock masses, do not change. The distribution shows a negative asymmetry, so the Gaussian anamorphosis has been performed once again in order to apply geostatistical techniques.

The transformed data have been used to compute directional variograms, applying the almost 3D approach, which has already proven to be the most effective. The maximum correlation direction is slightly rotated towards East and it exactly coincides with the mean discontinuity set developed parallel to the regional foliation, while the dip angle is equal to $10^{\circ}$. The invariance of scale has also been observed using the "dry RMR" data. The

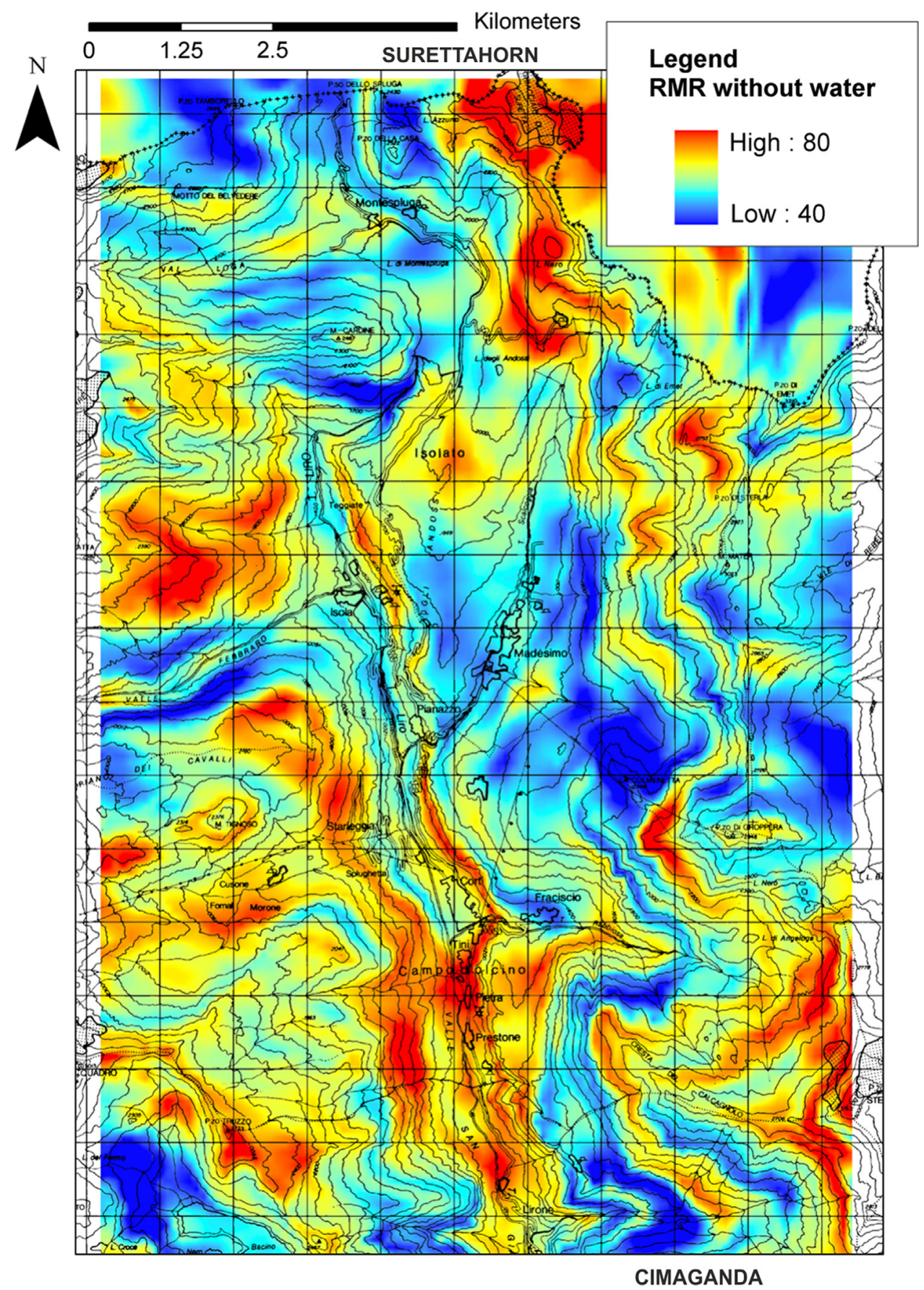

Fig. 10. Expected "dry Rock Mass Rating" values: the map of RMR values, for dry rock masses, estimated using the sequential Gaussian simulation with the almost threedimensional approach. 


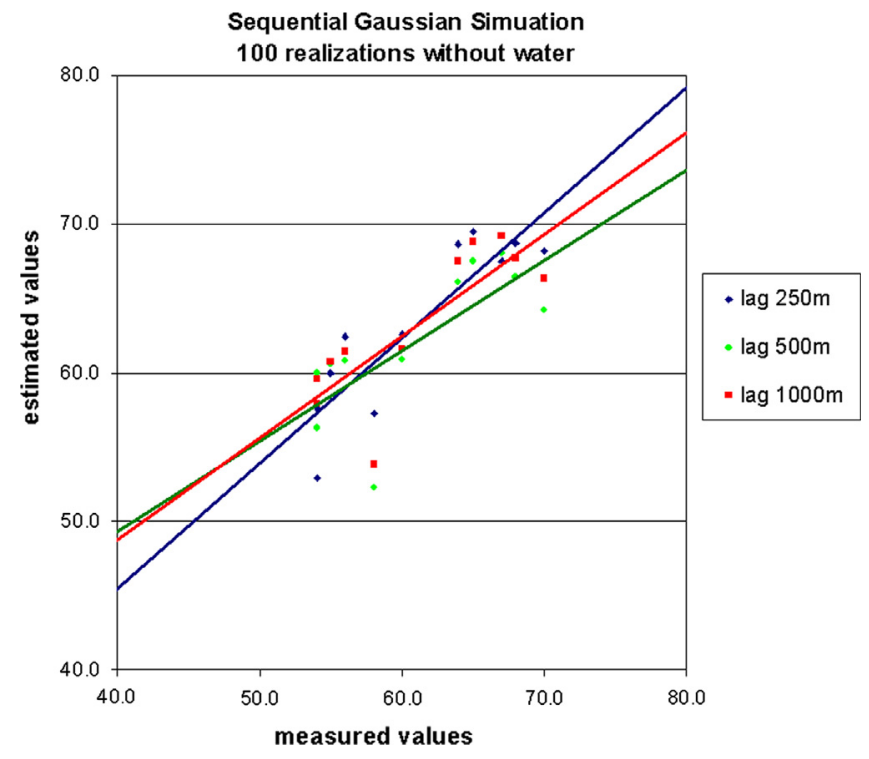

Fig. 11. Validation of "dry RMR" results: the graph associates measured values with estimated ones in new sampling locations.

theoretical models, which better fit the experimental variograms, are again spherical models for the variograms with bigger lags and a Gaussian model for the variogram with the shortest lag, which therefore shows a grater continuity than others. The features of the chosen variogram models are reported in Table 3.

All models confirm that when the lag increases the sill decreases, because increasing the distance the small heterogeneities are neglected, consequently the variance reduces; on the contrary the maximum range increases with lag distance, because the distance considered is longer. It is important to note that the nugget effect is equal to zero in all the variograms calculated without water and it can be considered a good clue, because typically the nugget effect is related to measurement errors or to short scale variability, with correlation range shorter than the sampling resolution, hence to the use of a not correct sampling grid. Considering the rock masses dry, the nugget effect is removed and so the estimation results should be improved.

Only the results of the estimation performed by sequential Gaussian simulation, carrying out 100 realizations, on a 3D grid are presented. The expected RMR values (Fig. 10) meet some important geological evidence: e.g. the low quality of rock masses, which outcrop on the South-East of the map with an arc shape, corresponds to the big niche of the historical Cimaganda landslide; the high quality of the Surettahorn rock masses, one of the highest mountains in Chiavenna Valley, on the North-East of the map, where the outcropping orthogneiss and migmatitic are characterized by a very low schistosity and wide spacing.

The validation (Fig. 11), performed as described in the 4.4 paragraph, shows that the best results come from the "dry RMR" dataset, especially with short lag, which is also able to capture small variability and heterogeneities. In conclusion, in this context, the use of "dry RMR" data improves appreciably the results.

\section{Conclusions}

Procedures and results about the estimation of geomechanical quality in an Italian Alpine valley has been presented here. From the data collected by 97 detailed geomechanical surveys, the rock mass quality, expressed by the Rock Mass Rating index, has been achieved. The examined rock masses exhibit similar geometrical and mechanical parameters in each surveyed site, all the RMR values fall within the 2nd and 3rd class, which correspond to good and fair quality, respectively. The analysis of each individual parameter, which composes the RMR index, suggests that the values are scattered independently from the lithology; this can be due to the fact that all the rock masses are poly-metamorphic and, although having different protoliths, they were subjected to similar geo-structural events. Therefore the rock mass quality is mostly controlled by large-scale brittle strain events; hence in the study area the regional geological structural history seems to have repercussions more important than the individual lithological changes. This peculiarity renders appropriate to consider the RMR as a single regionalized variable.

A geostatistical implementation has been carried out to examine the spatial variability of RMR index; its spatial structure has been investigated by means of the semivariogram analysis, considering both 2D and almost 3D approaches. Some correlations in the space have been determined at different scales, although the general correlation structure remains constant at all scales. The maximum correlation direction is towards NNE in the 2D model, whilst in the almost 3D variograms it has a dip of $20^{\circ}$, with direction towards NE. The maximum correlation direction and its dip are respected at each scale. The maximum correlation direction has a remarkable geological significance, because it coincides with the orientation of the discontinuity set developed almost parallel to the regional foliation, which is characterized by low spacing values and very high persistence, thus it is reasonable that this set affects the RMR index more than others.

The modelling of experimental variograms, through theoretical variograms, in agreement with the detected anisotropies, has allowed us to find the parameters needed to estimate variables far away from survey points. Afterwards the prediction has been performed through two different geostatistical techniques: ordinary kriging and sequential Gaussian simulation. A validation process, carried out on an independent dataset, reveals a quite good agreement between measured and estimated data. Ordinary kriging supplies the best results with the 2D grid, using long lag distance, but the extreme values are always smoothened, and this could lead to serious drawback especially when the zone with minimum or maximum rock quality have to be individuated. The best results (Fig. 10) are derived from sequential Gaussian simulation, performed on an almost 3D model (which takes into account also the vertical distance between survey locations), with a medium lag distance, which represents the best compromise between small and big geological heterogeneities considered in the variogram. As a consequence in an Alpine valley the remarkable elevation gradient cannot be neglected during both the variogram modelling and the prediction stage.

The resultant RMR predictive maps have been analyzed looking for correspondences between structural-geomorphological and the estimated geomechanical quality of rock masses, and since not completely satisfactory some considerations arise. Since the survey has been carried out on outcrops and in some different meteorological and weathering conditions, the parameter relative to the groundwater has not gathered in standard conditions, hence the evaluation of this parameter at each survey site is neither objective nor representative, leading to some inaccuracy in the RMR calculation. Hence, a new data set of RMR has been created assuming the same groundwater condition score (equal to dry state) for each survey site.

The maximum correlation direction of the new "dry RMR" dataset is slightly rotated toward E than those of the "wet" dataset, with a dip of $10^{\circ}$, it anyway follows the set related to foliation. The prediction performed with the "dry RMR" data furnishes the best results, with the capture of small heterogeneities in the model. It does not mean that water conditions could not be treated as regionalized variable or that they should be always removed. The improvement of the model without water should be due to 
different sampling conditions encountered during the surveys, which affect the datum. Actually supposing that all rock masses were dry, the nugget effect, which is often related to measurement errors, has been removed. Certainly in standard sampling situations and in areas with steady meteorological conditions water could be considered as the other parameter which composes the RMR and not separately.

In summary, geostatistical methods allow us to forecast the distribution of RMR values far away from the points of survey, in a very extent area. In Alpine region the best geostatistical technique seems to be the sequential Gaussian simulation founded on an almost 3D variogram whose anisotropy has to find correspondence to the geological features. Therefore simulations should be performed on the 3D domain and always validated with an independent data set. The resultant predictive map should reveal a relation with the regional geological and geomorphologial features of the area.

\section{Acknowledgements}

The research was financially supported by the Italian Ministry of Education, University and Research through the programme Research Project of National Interest (PRIN), and an Italian Ministerial PhD scholarship (2007). Thanks to the Valchiavenna Community, and to the colleagues Marco Masetti, Giovanni Pietro Beretta and Alessio Conforto.

\section{References}

[1] Bieniawski ZT. Engineering rock mass classification. New York: Wiley; 1989.

[2] Barton N, Lien R, Lunde J. Engineering classification of rock masses for the design of tunnel support. Rock Mech 1974;6(4):189-236.

[3] Isaaks EH, Srivastava RM. An introduction to applied geostatistics. Oxford: Oxford University Press; 1989.

[4] Villaescusa E, Brown ET. Characterising joint spatial correlation using geostatistical methods. In: Barton N, Stephansson O, editors. Rock joints. Rotterdam: Balkema; 1990. p. 115-22.

[5] Giani GP. Rock slope stability analysis. Rotterdam: Balkema; 1992.

[6] Matheron G. The theory of regionalized variables and its applications. Fontainebleau: Ecole de Mines; 1971.

[7] Long JCS, Billaux DM. From field data to fracture network modelling: an example incorporating spatial structure. Water Resour Res 1987;23(7): 1201-16.

[8] Young DS. Random vectors and spatial analysis by geostatistics for geotechnical applications. Math Geol 1987;19(6):467-79.

[9] Chilès JP. Fractal and geostatistical method for modelling a fracture network. Math Geol 1988;20(6):631-54.

[10] Billaux D, Chilès JP, Hestir K, Long J. Three-dimensional statistical modelling of a fractured rock mass - an example from the Fanay-Augères mine. Int J Rock Mech Min Sci 1989;26(3-4):281-99.

[11] Grigarten E. 3-D geometric description of fractured reservoir. Math Geol 1996;28(7):881-93.

[12] Meyer T, Einstein HH. Geologic stochastic modelling and connectivity assessment of fracture systems in the Boston area. Rock Mech Rock Eng 2002;35 (1):23-44

[13] Dowd PA, Xu C, Mardia KV, Fowell RJ. A comparison of methods for the stochastic simulation of rock fractures. Math Geol 2007:39(7):697-714.

[14] Koike K, Ichikawa Y. Spatial correlation structures of fracture systems for deriving a scaling law and modelling fracture distributions. Comput Geosc 2006:32:1079-95.

[15] Rafiee A, Vinches M. Application of geostatistical characteristics of rock mass fracture system in 3D model generation. Int J Rock Mech Min Sci 2008;45: 644-52.

[16] La Pointe PR Analysis of the spatial variation in rock mass properties through geostatistics. In: Proceedings of the 21st US rock mechanics symposium, 1980; p. $570-80$.

[17] Young DS. Indicator kriging for unit vectors: rock joint orientations. Math Geo $1987 ; 19(6): 481-501$

[18] Yu YF, Mostyn GR. Spatial correlation of rock joints. Probabilistic methods in geotechnical engineering. Rotterdam: Balkema; 1993.

[19] Tavchandjian O, Rouleau A, Archambault G, Daigneault R, Marcotte D. Geostatistical analysis of fractures in shear zones in the Chibougamau area: applications to structural geology. Tectonophysics 1997;269:51-63.

[20] Ozturk CA, Nasuf E. Geostatistical assessment of rock zones for tunnelling. Tunn Undergr Space Technol 2002;17:275-85.
[21] Escuder Viruete J, Carbonell R, Martí D, Pérez-Estaún A. 3-D stochastic modelling and simulation of fault zones in the Albala Granitic Pluton, SW Iberian Variscan Massif. J Struct Geol 2003;25:1487-506.

[22] Gumiaux C, Gapais D, Brun JP. Geostatistics applied to best-fit interpolation of orientation data. Tectonophysics 2003;376:241-59.

[23] Ellefmo SL, Eidsvik J. Local and spatial joint frequency uncertainty and its application to rock mass characterisation. Rock Mech Rock Eng 2009;42 (4):667-88.

[24] Oh S, Chung H, Lee DK. Geostatistical integration of MT and borehole data for RMR evaluation. Environ Geol 2004;46:1070-8.

[25] You K, Lee JS. Estimation of rock mass classes using the 3-dimensional multiple indicator kriging technique. Tunn Undergr Space Technol 2006;21 $(3-4): 229$.

[26] Stavropoulou M, Exadaktylos G, Saratsis G. A combined three-dimensional geological-geostatistical-numerical model of underground excavations in rock. Rock Mech Rock Eng 2007:40(3):213-43.

[27] Choi JY, Lee CI An estimation of rock mass rating using 3D-indicator kriging approach with uncertainty assessment of rock mass classification. In: Proceedings of the 11 th congress of the international society for rock mechanics, Lisbon, vol. 2, 2007; p. 1285-88.

[28] Exadaktylos G, Stavropoulou M. A specific upscaling theory of rock mass parameters exhibiting spatial variability: analytical relations and computational scheme. Int J Rock Mech Min Sci 2008;45:1102-25.

[29] Exadaktylos G, Stavropoulou M, Xiroudakis G, de Broissia M, Schwarz H. A spatial estimation model for continuous rock mass characterization from the specific energy of a TBM. Rock Mech Rock Eng 2008;41:797-834.

[30] Choi Y, Yoon SY, Park HD. Tunneling analyst: a 3D GIS extension for rock mass classification and fault zone analysis in tunneling. Comput Geosci 2009;35:1322-33.

[31] Kaewkongkaew K, Phien-wej N, Kham-ai D. Prediction of rock mass along tunnels by geostatistics. In: Fuenkajorn, Phien-wej, editors. Rock mechanics; 2011. p. 269-76.

[32] Froitzheim N, Schdmid ST, Conti P. Repeated change from crustal shortening to orogenparallel extension in the Austroalpine units of Graubünden. Eclogae Geol Helvetiae 1994;87(2):559-612.

[33] Marquer D, Baudin TH, Peucat JJ, Persoz F. Rb-Sr mica ages in the Alpine shear zones of the Truzzo granite: timing of the tertiary alpine P-T deformations in the Tambò nappe (Central Alps, Switzerland). Eclogae Geol Helvetiae 1994;85 (3):1-61.

[34] Schmid SM, Zingg A, Handy M. The kinematics of movements along the insubric line and the emplacement of the Ivrea zone. Tectonophysics 1987; 135:47-66.

[35] Baudin T, Marquer D, Barfety JC, Kerckhove C, Persoz F. A new stratigraphical interpretation of the mesozoic cover of the Tambò and Suretta nappes: evidence for early thin-skinned tectonics (Swiss Central Alps). Comptes Rendus de l' Acad des Sci Paris 1995;321(5):401-8.

[36] Huber RH, Marquer D. Tertiary deformation and kinematics of the southern part of the Tambò and Suretta nappes (Val Bregaglia, Eastern Swiss Alps). Schweiz Min Petrogr Mitt 1996;76:383-97.

[37] Baudin TH, Marquer D. Metamorphism and deformation in the Tambò nappe (Swiss Central Alps): evolution of the phengite substitution during Alpine deformation. Schweiz Min Petrogr Mitt 1993;73:285-99.

[38] ISRM. Suggested methods for the quantitative description of discontinuities in rock masses. Int J Rock Mech Min Sci 1978;15(6):319-68.

[39] Hoek E, Brown ET. Practical estimates of rock mass Strength. Int J Rock Mech Min Sci 1997;34(8):1165-86.

[40] Palmstrom A The volumetric joint count: a useful and simple measure of the degree of rock mass jointing. In: Proceedings of the IAEG congress, New Delhi, 1982; p. V. 221-28.

[41] Ferrari F, Apuani T, Giani GP Geomechanical surveys and geostatistical analyses in Valchiavenna (Italian Central Alps). In: Proceedings of the 8th international symposium on field measurement in geomechanics, Berlin; 2011.

[42] Ferrari F, Apuani T, Giani GP. Analisi spaziale e previsionale delle proprietà geomeccaniche degli ammassi rocciosi della Val San Giacomo (SO), mediante tecniche geostatistiche. GEAM - Geoing Ambient e Min 2012:1:21-30.

[43] Barton NR, Choubey V. The shear strength of rock joints in theory and practice. Rock Mech 1977;10(1-2):1-54.

[44] Apuani T, Giani GP, Merri A Geomechanical studies of an alpine rock mass. In: Proceedings of the 3rd CAN-US rock mechanics symposium, Toronto; 2009.

[45] Priest SD, Hudson JA. Discontinuity spacing in rock. Int J Rock Mech Min Sci $1976 ; 13(5): 135-48$

[46] Grigarten E, Deutsch CV. Variogram interpretation and modelling. Math Geol 2001;33(4):507-34.

[47] Pardo-Igùzquiza E, Dowd PA. Normality tests for spatially correlated data. Math Geol 2004:36(6):659-81.

[48] Shapiro SS, Wilk MB. An analysis of variance test for normality (complete samples). Biometrika 1965;52(3-4):591-611.

[49] Lilliefors HW. On the Kolmogorov-Smirnov test for normality with mean and variance unknown. J Am Stat Assoc 1967;62(318):399-402.

[50] Goovaerts P. Geostatistics for natural resources evaluation. Oxford: Oxford University Press; 1997.

[51] Isaaks E, Srivastava RM. An introduction to applied geostatistics. New York: Elsevier; 1989.

[52] Papoulis A. Probability, random variables and stochastic processes. Singapore: McGraw-Hill; 1984. 
[53] Caers J, Zhang T. Multiple-point geostatistics: a quantitative vehicle for integrating geologic analogs into multiple reservoir models, 80. Vancouver, Canada: American Association of Petroleum Geologists; 2004; 383-94.

[54] Marinoni O. Improving geological models using a combined ordinaryindicator kriging approach. Eng Geol 2003;69:37-45.

[55] Remy N, Boucher A, Wu J. Applied geostatistics with SGeMS: a user's guide. New York: Cambridge University Press; 2008.
[56] Journel AG, Huijbregts C. Mining geostatistics. London: Academic Press; 1978.

[57] Barnes RJ. The variogram sill and the sample variance. Math Geol 1991;23 (4):763-8.

[58] Kitanidis PK. Introduction to geostatistics: applications in hydrogeology. Cambridge: Cambridge University Press; 1997. 